\title{
The views of medical students and junior doctors on pre-graduate clinical teaching
}

\author{
B Ward, G Moody, JF Mayberry
}

\begin{abstract}
Summary
A total of 277 third and fourth year medical students and 304 house officers and senior house officers were asked to prioritise the content and methods of clinical teaching. Response rates were poor, but similar to that in market surveys. Bedside teaching and medical clerking were considered the most valuable methods of teaching and training in practical procedures such as venepunctures and urinary catheterisation was seen as valuable. The design of new curricula in medical education will need to accommodate the views of its clients.
\end{abstract}

Keywords: education, teaching methods, medical students, junior doctors

Medical training is under review. From early undergraduate days through to an established post as a consultant, medical students and doctors are in an educational milieu. The acquisition of new knowledge and the updating and refreshing of clinical skills is now the responsibility of all practitioners. The techniques used in medical schools are likely to be adopted throughout the profession and their critical evaluation will be of benefit to all those involved in medical education.

As medical care becomes increasingly concerned with patient satisfaction and as those patients become involved in setting and monitoring standards, there is a growing interest in the nature and quality of teaching given to tomorrow's doctors. In parallel with these developments we are likely to see more involvement of medical students and junior doctors in defining the nature of their courses and commenting critically on the quality of teaching they receive. The overriding need is to ensure that the training given to present medical students and junior doctors will equip them to practice well into the next century. With these concepts in mind, a pilot study of clinical medical students and junior doctors in Leicester was undertaken to identify areas of interest and concern to them, although clearly this may not meet the future needs of society.

\section{Methods}

Questionnaires were sent to all medical students in the third and fourth year of their clinical training at the Medical School in Leicester $(n=277)$. Identical questionnaires were sent to all house officers and senior house officers working in the three main acute hospitals in Leicester $(n=304)$. The questionnaires were anonymous and only distributed once. They were developed independently of any involvement of medical school personnel and were not linked to any educational assessment.

Respondents were asked about the value of medical clerking, bedside tuition and supervised teaching on the wards and in out-patient departments. Comments on the value of formal teaching by topic seminar, case presentations, observation of procedures and the work of multidisciplinary groups, data interpretation sessions, and mock clinical examinations were sought. The teaching of practical procedures such as venepuncture, intravenous cannulation, urinary catheterisation, urine analysis and blood sugar monitoring was also investigated.

Each student was asked to report on each subject using a three-point scale of: 'very important', 'fairly important' or 'not very important'. Results are presented for those items considered 'very important'.

A separate sample of 21 students were asked to mark on a scale of 1 (most significant) to 4 (least significant) how significant pre-graduate clinical teaching was in: stopping being sued, giving better care to patients, getting a job, and passing exams.

\section{Results}

Only 108 of 277 (39\%) medical students completed and returned the questionnaire. The response rate of $32 \%$ from the 304 doctors was similar. Bedside teaching and medical clerking were seen as the most valued methods of teaching (table 1). Junior doctors were significantly less impressed by unsupervised review of patients, both on the ward and in outpatients than medical students (statistical analysis was performed on untransformed data).

Table 2 shows the teaching techniques identified as 'very important'. Sessions on data and radiological interpretation were considered most valuable by medical students, followed by case note presentation. In contrast, significantly more junior doctors considered mock clinical examinations very important. Although only $17 \%$ of medical students favoured involvement in multidisciplinary teams, this was significantly greater than for junior doctors. 
Table 1 Evaluation of pre-graduate teaching by medical students and junior doctors

\begin{tabular}{|c|c|c|c|c|}
\hline \multirow[b]{2}{*}{ Item } & \multicolumn{2}{|c|}{ Medical students (\%) $(n=108)$} & \multicolumn{2}{|c|}{ Funior doctors $(\%)(n=97)$} \\
\hline & $V I$ & $N V I$ & $V I$ & $N V I$ \\
\hline Bedside teaching & 90 & 1 & 81 & 3 \\
\hline Medical clerking & 81 & 2 & 86 & 3 \\
\hline Supervised review of ward-based patients & 66 & 5 & 67 & 5 \\
\hline Unsupervised review of ward-based patients & 61 & 10 & $47^{\star}$ & $7^{\star}$ \\
\hline Supervised observation in out-patients & 45 & 9 & 45 & 14 \\
\hline Unsupervised observation in out-patients & 44 & 17 & $28^{\star \star}$ & $32^{\star \star}$ \\
\hline
\end{tabular}

$\mathrm{VI}=$ very important; $\mathrm{NVI}=$ not very important

${ }^{\star} \mathrm{z}=-1.97, \mathrm{p}<0.05 ;{ }^{\star \star} \mathrm{z}=-2.47, \mathrm{p}<0.01$

Table 2 Pre-graduate teaching techniques preferred by medical students and junior doctors

\begin{tabular}{|c|c|c|c|c|}
\hline \multirow[b]{2}{*}{ Item } & \multicolumn{2}{|c|}{ Medical students $(\%)(n=108)$} & \multicolumn{2}{|c|}{ funior doctors (\%) (n=97) } \\
\hline & $V I$ & $N V I$ & $V I$ & $N V I$ \\
\hline Data and radiological interpretation & 80 & 2 & 74 & 6 \\
\hline Case note presentation & 62 & 5 & 57 & 7 \\
\hline Mock clinical examinations & 56 & 11 & $80^{\star}$ & $3^{\star}$ \\
\hline Topic seminars & 41 & 7 & 39 & 7 \\
\hline 'Feed-back' sessions on performance & 29 & 22 & 35 & 7 \\
\hline Observing procedures & 20 & 22 & 14 & 27 \\
\hline Involvement with multidisciplinary teams & 17 & 34 & $5^{\star \star}$ & $49^{\star \star}$ \\
\hline
\end{tabular}

$\mathrm{VI}=$ very important; $\mathrm{NVI}=$ not very important

${ }^{\star} \mathrm{z}=-3.79, \mathrm{p}<0.001 ;{ }^{\star \star} \mathrm{z}=2.6, \mathrm{p}<0.01$

Table 3 Medical students' and junior doctors' evaluation of need for pre-graduate training in practical skills

\begin{tabular}{|c|c|c|c|c|}
\hline \multirow[b]{2}{*}{ Item } & \multicolumn{2}{|c|}{ Medical students (\%) $(n=108)$} & \multicolumn{2}{|c|}{ funior doctors $(\%)(n=97)$} \\
\hline & $V I$ & $N V I$ & $V I$ & $N V I$ \\
\hline Venepuncture & 75 & 4 & 76 & 8 \\
\hline Intravenous cannulation & 80 & 3 & 80 & 5 \\
\hline Catheterisation & 60 & 4 & 69 & 5 \\
\hline Blood sugar monitoring & 52 & 14 & $33^{\star}$ & $20^{\star}$ \\
\hline Urine analysis & 47 & 4 & $25^{\star \star}$ & $30^{\star \star}$ \\
\hline
\end{tabular}

VI = very important; NVI = not very important

${ }^{\star} \mathrm{z}=-2.7, \mathrm{p}<0.01 ;{ }^{\star \star} \mathrm{z}=-3.5, \mathrm{p}<0.001$

Table 4 Medical students' assessment of importance of clinical training in various items $(n=21)$. Scores ranged from 1 to 4 ; the lower the score the more important the item

\begin{tabular}{lllll}
\hline Item & Mean score & $S D$ & Median & Interquartile range \\
\hline Stop being sued & 3.3 & 1.0 & 4 & $3-4$ \\
Giving better care to patients & 1.8 & 0.9 & 2 & $1-2$ \\
Getting a job & 2.8 & 0.9 & 2 & $2-3$ \\
Passing exams & 2.4 & 0.9 & 2 & $2-3$
\end{tabular}

Venepuncture and urinary catheterisation were seen as the most valuable practical skills in which to receive training (table 3 ). Interest in the management structure of hospitals was limited, and decreased after qualification, with $48 \%$ of students ( $77 \%$ of junior doctors) considering it 'unimportant' and only $12 \%$ of students ( $4 \%$ of junior doctors) considering it 'very important'.

In the smaller survey of 21 medical students, the role of pre-graduation clinical training was considered to be significantly more important in helping students to give better care to patients than in passing their exams (table 4) (Mann Whitney, adjusted for ties $\mathrm{p}<0.02$ ). Its role in passing exams and getting a job were considered equally important.

\section{Discussion}

Medical students and junior doctors want goalorientated teaching which is of relevance to clinical care. It needs to be based on the ward and in out-patient departments. ${ }^{1,2}$ However, the emphasis must be on a supervised approach to learning which is real rather than 
illusory. For example, waiting for long-postponed case discussions is not considered profitable. Although one way of overcoming this difficulty is through regular topic seminars and discussion groups, such an approach was not gain favoured by either students or doctors. The old-style apprentice approach to the training of doctors clearly meets some of these criticisms, but cannot adequately deal with the rapid advances in knowledge and technology which characterise medicine at the end of the twentieth century. ${ }^{3}$

This study may be criticised because of its parochial nature. Can observations in Leicester be generalised to medical teaching in the rest of Britain or even Europe ${ }^{4}$ In recent years, Leicester has adopted a portfolio-based learning approach to medical education. Some of the participants in this study had trained in an earlier era and there will be a need to repeat this study once this new method of teaching has become fully established throughout the medical school. Clearly there is a need for a rational review of medical training and the introduction of regular monitoring of its effectiveness. This pilot study was directed at what medical students and junior doctors want and think they need, and took no account of

1 Alexander DA, Haldane JD. Medical education: the observations of pre-clinical and clinical teaching. Med Educ 1981; 15: 4-10.

2 Bolger C, Staines A. Survey of student opinion of the medical curriculum at Trinity College, Dublin, Republic of medical curriculum at Trinity College,

3 Older J. Medical students design - their ideal medical school. N Z Med f 1976; 184: 239-41.

\section{Summary points}

- medical students considered the role of pregraduation clerical training as significantly more important in helping them to give better care to patients than in passing their exams

- junior doctors were significantly less impressed by unsupervised review of patients, both on the ward and in out-patients

- significantly more junior doctors than medical students considered mock clinical examinations very important

- junior doctors considered pre-graduate teaching on urinary analysis and blood sugar monitoring of less value than medical students did

the views of senior supervising doctors, their future employers or indeed patients. Clearly there may be conflict between 'what they want and what they need'.

Medical students and junior doctors have a reputation for being keen to learn. Enthusiasm for the clinical experience is still the hallmark of the profession and will continue to benefit from careful nurturing.

4 Rosinski EF, Hill P. Student expectations and personal perceptions as an approach to course evaluation. Med Educ 1986; 20: $228-33$.

5 Yonke AM. The art and science of clinical teaching. Med Educ 1979; 13: 86-90. 